\title{
Measurement of the Entire Spectrum of Dental Caries Using an Innovative Tool: CAST Index for Children Aged 11 to 14 Years of Udupi Taluk, India
}

\author{
${ }^{1}$ Shatakshi Srivastava, ${ }^{2}$ Deepak Singhal, ${ }^{3}$ Shashidhar Acharya
}

\section{ABSTRACT}

Introduction: One of the most prevalent known chronic diseases worldwide is dental caries. The caries assessment spectrum and treatment (CAST) index-Frencken JE et al. (2011) records all the clinical stages of caries spectrum under nine codes.

Materials and methods: The prevalence of the entire spectrum of caries was assessed among children aged 11 to 14 years, of Udupi Taluk, via a cross-sectional study. 800 children were examined under natural light, with sterilized plane mouth mirrors and periodontal probe of $0.5 \mathrm{~mm}$ ball tip. The most severe condition was considered for each participant and was recorded.

Results: Thirty-five percent had permanent teeth that were caries free. No children had preventive fillings in permanent teeth, and only $9 \%$ had restorations. Thirty percent of children had dental caries (codes $3-5$ ) whereas $18 \%$ were suffering from after effects of severe untreated dental caries of permanent teeth (CAST code 6 or 7 ). Eight percent had at least one tooth removed due to caries.

Discussion: The reported findings were higher than studies done on adults in an Asian population using CAST index.

Conclusion: CAST index as a measurement tool, gives an accurate picture of the hidden iceberg of disease (dental caries) prevalent in Indian children.

Keywords: Adolescent, Child, Dental caries, Indices.

How to cite this article: Srivastava S, Singhal D, Acharya S. Measurement of the Entire Spectrum of Dental Caries Using an Innovative Tool: CAST Index for Children Aged 11 to 14 Years of Udupi Taluk, India. J Contemp Dent 2018;8(2):83-87.

Source of support: Nil

Conflict of interest: None

\footnotetext{
${ }^{1}$ Lecturer, ${ }^{2}$ Associate Professor, ${ }^{3}$ Professor

${ }^{1}$ Department of Public Health Dentistry, Mahatama Gandhi Mission's Dental College and Hospital, Kamothe, Navi Mumbai, Maharashtra, India

${ }^{2,3}$ Department of Public Health Dentistry, Manipal College of Dental Sciences, Manipal, Karnataka, India

Corresponding Author: Shatakshi Srivastava, Lecturer, Department of Public Health Dentistry Mahatama Gandhi Mission's Dental College and Hospital, Kamothe, Navi Mumbai, Maharashtra, India, e-mail: drshatakshi.srivastava@gmail. com
}

\section{INTRODUCTION}

One of the most prevalent chronic diseases worldwide is dental caries. A complicated interaction between acidproducing bacteria, fermentable carbohydrates and host factors like saliva and tooth over a period leads to the development of dental caries, also known as tooth decay. ${ }^{1}$ In 2003, the world oral health report reported 60 to $90 \%$ of school children in the western world to be suffering from dental caries. Reports have shown that most prevalent oral disease in several Asian and Latin American countries is dental caries. ${ }^{2}$ The WHO oral health database for 12-year-old has shown that the caries experience (DMF) of middle- and low-income countries have been on a steady increase in the 1990s. ${ }^{3}$ There is a very high proportion of untreated dentine lesions that have progressed to cavitation stage, in this age group in these countries. ${ }^{3}$

Dental caries being the most common disease of the oral cavity is of prime importance to the dental healthcare providers. This is because of the various problems caused by dental caries that include pain, the lack of sleep, absence from the workplace and physical deformity. ${ }^{4}$ Valid and reliable recording instruments are quintessential from the public health and clinical perspective. These instruments give information for the various type of study designs like case finding, descriptive epidemiology, and experimental epidemiology.

The caries indices that have been used in the scientific literature over the past 50 years are decay-missing -filled (DMFT) index and indices. These indices have a " $\mathrm{D}$ " component that includes decay because of caries. The criteria for a decayed tooth is one in which visible cavitation and caries have progressed until the dentine. ${ }^{5}$ These indices did not account for white spot lesions which have shown an increasing trend in the western world due to the widespread use of fluoride. For the inclusion of these white spot lesions, the international caries detection and assessment system (ICDAS) index was developed by Ismail et al. ${ }^{6}$

Another disadvantage of only utilizing the DMFT index to record dental caries is that it did not take into account pulpally involved teeth and the consequences of severe dental caries, i.e., abscess, fistula, ulceration. If a tooth was decayed, it was counted in the D component of DMFT irrespective of the level of dental caries, 
i.e, decay involving dentine and or pulp was recorded as D in DMFT index. This lead to the development of PUFA index by Monse et al. ${ }^{7}$

Despite the development of new indices like ICDAS and PUFA index, to record the entire caries spectrum was proven to be difficult. ${ }^{8}$ Many problems were encountered during reporting results after using ICDAS II and PUFA separately in a survey in a child population in Brazil. All these problems lead to the development of CAST index, which is a comprehensive tool to record the entire spectrum of dental caries. ${ }^{8}$

There are hardly any studies done in India that assess the entire caries spectrum in the children using CAST index. With this background, the objective of this study was to record the entire spectrum of dental caries in a child population aged between 11 to 14 years in Udupi Taluk, India.

\section{MATERIALS AND METHODS}

The prevalence of the entire spectrum of caries was assessed using CAST index of children aged between 11 to 14 years, of Udupi Taluk. A cross-sectional study was done. Before starting, the study, ethical clearance was obtained from the Kasturba Hospital Ethics Committee, Kasturba Hospital, Manipal (IEC 124/2014).

A sample size of 769 was arrived at, assuming the estimated prevalence of disease (dental caries) in the study population to be $20 \%$, with a margin of error at $4 \%$. Since cluster sampling was done, a design effect of two was taken into consideration to calculate the final sample size. Considering a few chances of incomplete responses for the entire study, the sample size was fixed at 800 . A list of schools in Udupi Taluk was obtained from Office of the Block Education Officer, Department of Public Education, Udupi Division, Udupi. The study was conducted in randomly selected nine schools. Permission to examine the school children was obtained from the teachers of the respective schools. A written parental consent was obtained.

\section{Examiner Training}

The training and calibration sessions were carried out by a senior epidemiologist. In the training session, there was a theoretical explanation about the CAST instrument for 1.5 hours. The practical session was carried out for 2 hours. For this, a total of 10 extracted teeth were examined and scored by the trainee examiner. CAST index recording in this study, was done by a single trained examiner.

\section{Inclusion Criteria}

The study was conducted on children of 11 to 14 years (as of their last birthday), between 6 to 10th standard, studying in schools of Udupi taluk who were present on the day of examination and were willing to participate, whose parents had provided consent.

\section{Exclusion Criteria}

Children who were undergoing orthodontic therapy or who had cleft lip palate or any other craniofacial anomalies.

The examination was carried out under natural light, with sterilized plain dental mouth mirror and periodontal probe with $0.5 \mathrm{~mm}$ ball tip. Before scoring the teeth were wiped with a cotton wool roll to dry its surface. A dental examination was carried out for all teeth present in the participant's mouth. Each tooth's surface was recorded separately. If two conditions were present on the same surface, e.g., a filling in one pit and a dentin lesion in another, the higher score was recorded. An abscess or a fistula if it was present, all surfaces were score code. ${ }^{7}$ The most severe condition was considered for each participant and was recorded. ${ }^{9}$ Along with this other demographic data like name, age, gender was also recorded for each study participant. The descriptive statistics were done to calculate the percentage of children with the highest CAST score. The first permanent and deciduous molars CAST index was also calculated separately.

Codes and descriptions of the CAST index ${ }^{8}$

\begin{tabular}{|c|c|c|}
\hline $\begin{array}{l}\text { Characte- } \\
\text { ristic }\end{array}$ & Code & Description \\
\hline Sound & 0 & $\begin{array}{l}\text { Sound. No visible evidence of a distinct } \\
\text { carious lesion }\end{array}$ \\
\hline Sealed & 1 & $\begin{array}{l}\text { Pits and fissures sealant complete or } \\
\text { partial }\end{array}$ \\
\hline Restored & 2 & $\begin{array}{l}\text { A cavity has been restored with an (in) } \\
\text { direct restorative material }\end{array}$ \\
\hline Enamel & 3 & $\begin{array}{l}\text { Distinct visual change of enamel with } \\
\text { a visible discoloration. No dentine } \\
\text { involvement }\end{array}$ \\
\hline \multirow[t]{2}{*}{ Dentin } & 4 & $\begin{array}{l}\text { Internal caries-related discoloration in } \\
\text { dentine. The lesion appears as shadows } \\
\text { of discolored dentin visible through } \\
\text { enamel which may or may not exhibit a } \\
\text { visible localized breakdown }\end{array}$ \\
\hline & 5 & $\begin{array}{l}\text { Distinct cavitation into dentine. No pulp } \\
\text { involovement }\end{array}$ \\
\hline \multirow[t]{2}{*}{ Pulp } & 6 & $\begin{array}{l}\text { Involvement of pulp chamber or root } \\
\text { fragments remaining }\end{array}$ \\
\hline & 7 & Abscess/fistula or sinus tract present \\
\hline Lost & 8 & $\begin{array}{l}\text { Tooth has been removed because of } \\
\text { dental caries. }\end{array}$ \\
\hline Other & 9 & $\begin{array}{l}\text { Does not match with any of the other } \\
\text { categories }\end{array}$ \\
\hline
\end{tabular}

\section{RESULTS}

In this study, $10.4 \%(\mathrm{n}=83)$ were 11 years old, $16.9 \%$ ( $n=135)$ were 12 years old, with a majority of them i.e, $33.6 \%(n=269)$ and $39.1 \%(n=313)$ being 13 years 
Measurement of the Entire Spectrum of Dental Caries Using an Innovative Tool

and 14 years old respectively. Fifty-three percent $(\mathrm{n}=424)$ attended private schools and 47.0\% $(\mathrm{n}=376)$ attended government schools.

\section{DISCUSSION}

As a tool for entire caries spectrum recording, CAST index is an apt epidemiological tool for caries detection. ${ }^{10}$ It evaluates caries in an orderly manner that is from sound teeth, through sealants, fillings, and enamel and dentine lesions, to those progressed into the pulp and tooth-surrounding tissues. ${ }^{11,12}$

The CAST index was developed as it was cumbersome to record and report early enamel lesions using ICDAS 2 and consequences of severe dental caries using PUFA along with DMFT indices. PUFA complements ICDAS2 as they have are no overlapping scores. ${ }^{8}$ The newly developed CAST index has combined all three indices taking into account Missing (CAST code 8) and Filled Component (CAST code 2) of DMFT index. Therefore, CAST index has an edge over other newer caries indices, that the DMFT/dmft score can be calculated from it, beneficial universalcomparison. ${ }^{10}$

The previous study has demonstrated CAST Index to be a good instrument in epidemiological surveys in India after a couple of modifications of the original index. ${ }^{13}$ Its application regarding Indian context can be justified considering the varied population with different socioeconomic and cultural backgrounds and the fact that entire dental caries spectrum can be recorded at once using CAST index. ${ }^{13}$

In this study, barely $35 \%$ had permanent teeth that were caries free. No children had preventive fillings in permanent teeth and only $9 \%$ had fillings. Thirty percent of the children had dental caries (Codes 3-5) whereas 18\% were suffering from consequences of severe untreated dental caries in permanent teeth (CAST code 6 or 7). Eight percent had at least one tooth removed due to caries (Table 1 and Graph 1). The results obtained by this study were higher to another study done in Asia using CAST index in adults where the majority of the teeth $84.8 \%$ were caries free. ${ }^{12}$ This result should be carefully interpreted as in our study main focus was on permanent teeth since the age group 11 to 14 years has mostly permanent dentition.

The presence of no preventive fillings is an alarming sign in children and highlights the fact that parents or care givers do not consider prevention of dental caries via sealants as important. In India, prevention of dental caries using sealants is a largely unexplored field on a public health level. This finding is similar to another study done in India, where children had not been treated with any preventive fillings. ${ }^{10}$

The permanent first molars and primary second molars were also assessed separately for the prevalence of decay. In first permanent molars, enamel and dentin caries prevalence (CAST codes 3 to 5) ranged from $8.4 \%$
Table 1: CAST index recording for permanent dentition (maximum score for each individual was recorded)

\begin{tabular}{clcc}
\hline Code & Description & $N$ & $\%$ \\
\hline 0 & Sound & 280 & 35 \\
1 & Sealed & 0 & 0 \\
2 & Restored & 72 & 9 \\
3 & Distinct visual change in enamel & 104 & 13 \\
4 & Internal caries-related discoloration in & 104 & 13 \\
& dentin & 52 & 4 \\
5 & Distinct cavitation into dentine & 120 & 15 \\
6 & Involvement of pulp chamber & 24 & 3 \\
7 & Abscess/fistula & 64 & 8 \\
8 & Tooth has been removed because of dental & & \\
& caries & 0 & 0 \\
9 & Does not match with any of the other & & \\
\hline
\end{tabular}

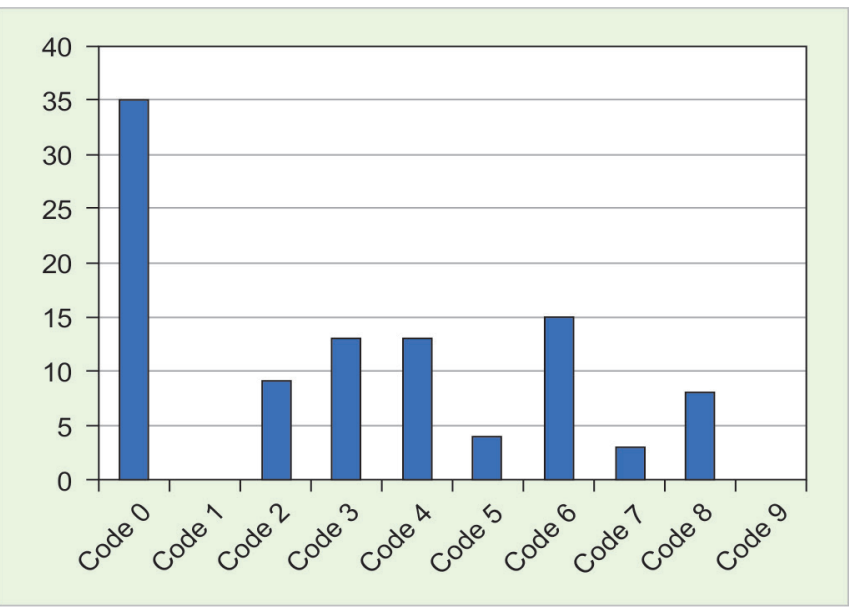

Graph 1: Representation of permanent dentition as per CAST index

Table 2: CAST index recording for permanent first molars

\begin{tabular}{|c|c|c|c|c|}
\hline $\begin{array}{l}\text { Tooth } \\
\text { number } \\
N(\%)\end{array}$ & $\begin{array}{l}\text { Upper } \\
\text { right first } \\
\text { permanent } \\
\text { molar }\end{array}$ & $\begin{array}{l}\text { Upper } \\
\text { left first } \\
\text { permanent } \\
\text { molar }\end{array}$ & $\begin{array}{l}\text { Lower } \\
\text { left first } \\
\text { permanent } \\
\text { molar }\end{array}$ & $\begin{array}{l}\text { Lower } \\
\text { right first } \\
\text { permanent } \\
\text { molar }\end{array}$ \\
\hline Code 0 & $\begin{array}{l}695 \\
(86.9)\end{array}$ & $\begin{array}{l}704 \\
(88.0)\end{array}$ & $\begin{array}{l}560 \\
(70.0)\end{array}$ & $\begin{array}{l}554 \\
(69.3)\end{array}$ \\
\hline Code 1 & $\begin{array}{l}0 \\
(0)\end{array}$ & $\begin{array}{l}0 \\
(0)\end{array}$ & $\begin{array}{l}0 \\
(0)\end{array}$ & $\begin{array}{l}0 \\
(0)\end{array}$ \\
\hline Code 2 & $\begin{array}{l}4 \\
(0.5)\end{array}$ & $\begin{array}{l}5 \\
(0.6)\end{array}$ & $\begin{array}{l}14 \\
(1.8)\end{array}$ & $\begin{array}{l}15 \\
(1.9)\end{array}$ \\
\hline Code 3 & $\begin{array}{l}50 \\
(6.3)\end{array}$ & $\begin{array}{l}40 \\
(5)\end{array}$ & $\begin{array}{l}94 \\
(11.8)\end{array}$ & $\begin{array}{l}114 \\
(14.3)\end{array}$ \\
\hline Code 4 & $\begin{array}{l}21 \\
(2.6)\end{array}$ & $\begin{array}{l}19 \\
(2.4)\end{array}$ & $\begin{array}{l}59 \\
(7.4)\end{array}$ & $\begin{array}{l}56 \\
(7.0)\end{array}$ \\
\hline Code 5 & $\begin{array}{l}2 \\
(0.3)\end{array}$ & $\begin{array}{l}8 \\
(1)\end{array}$ & $\begin{array}{l}19 \\
(2.4)\end{array}$ & $\begin{array}{l}9 \\
(1.1)\end{array}$ \\
\hline Code 6 & $\begin{array}{l}24 \\
(3.0)\end{array}$ & $\begin{array}{l}20 \\
(2.5)\end{array}$ & $\begin{array}{l}46 \\
(5.8)\end{array}$ & $\begin{array}{l}47 \\
(5.9)\end{array}$ \\
\hline Code 7 & $\begin{array}{l}2 \\
(0.3)\end{array}$ & $\begin{array}{l}2 \\
(0.3)\end{array}$ & $\begin{array}{l}1 \\
(.1)\end{array}$ & $\begin{array}{l}0 \\
(0)\end{array}$ \\
\hline Code 8 & $\begin{array}{l}1 \\
(0.1)\end{array}$ & $\begin{array}{l}1 \\
(.1)\end{array}$ & $\begin{array}{l}7 \\
(0.9)\end{array}$ & $\begin{array}{l}4 \\
(0.5)\end{array}$ \\
\hline Code 9 & $\begin{array}{l}0 \\
(0)\end{array}$ & $\begin{array}{l}1 \\
(.1)\end{array}$ & $\begin{array}{l}0 \\
(0)\end{array}$ & $\begin{array}{l}0 \\
(0)\end{array}$ \\
\hline
\end{tabular}




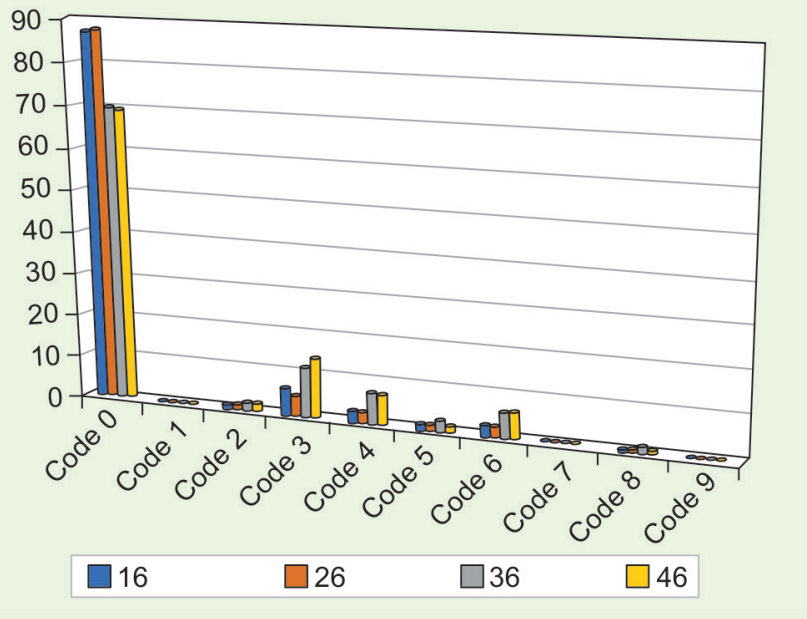

Graph 2: Representation of first permanent molars caries spectrum as per CAST index

to as high as $22.4 \%$. The prevalence of consequences of severe untreated decay (CAST Codes 5 and 6) also ranged from 3.3 to $5.9 \%$ (Table 2, Graph 2). The CAST index shows that up to $6 \%$ permanent first molars are pulpally decayed at the age of 11 to 14 years itself. This shows the poor oral health of the children, as pulpally involved teeth lead to loss of school going hours with an overall decrease in the quality of life. ${ }^{7}$

For primary second molars, enamel and dentin caries prevalence ranged from 2.3 to $2.9 \%$ whereas consequences of untreated decay were between 1.5 to $2.6 \%$ (Table 3, Graph 3). This was lesser than other studies. ${ }^{7,10,14}$ This could due to a drawback in the study design, as the study population comprised of children between 11 to 14 years of which some children had undergone natural shedding of primary second molars.

Table 3: CAST index recording for deciduous second molars

\begin{tabular}{lllll}
\hline Tooth & \multicolumn{2}{l}{ Upper right Upper left } & Lower left & Lower right \\
second & second & second & second \\
number & deciduous & deciduous & deciduous & deciduous \\
N (\%) & molar & molar & molar & molar \\
\hline Code 0 & 750 & 765 & 752 & 758 \\
& $(95.0)$ & $(95.6)$ & $(94.0)$ & $(94.8)$ \\
Code 1 & 0 & 0 & 0 & 0 \\
& $(0)$ & $(0)$ & $(0)$ & $(0)$ \\
Code 2 & 1 & 0 & 2 & 2 \\
& $(0.1)$ & $(0)$ & $(0.3)$ & $(0.3)$ \\
Code 3 & 8 & 4 & 8 & 6 \\
& $(1.0)$ & $(0.5)$ & $(1.0)$ & $(0.8)$ \\
Code 4 & 8 & 11 & 9 & 7 \\
& $(1.0)$ & $(1.4)$ & $(1.1)$ & $(0.9)$ \\
Code 5 & 6 & 5 & 6 & 5 \\
& $(0.8)$ & $(0.6)$ & $(0.8)$ & $(0.6)$ \\
Code 6 & 15 & 12 & 21 & 20 \\
& $(1.9)$ & $(1.5)$ & $(2.6)$ & $(2.5)$ \\
Code 7 & 0 & 0 & 0 & 0 \\
& $(0)$ & $(0)$ & $(0)$ & $(0)$ \\
Code 8 & 1 & 1 & 1 & 2 \\
& $(0.1)$ & $(.1)$ & $(0.1)$ & $(0.3)$ \\
Code 9 & 0 & 0 & 0 & 0 \\
& $(0)$ & $(0)$ & $(0)$ & $(0)$ \\
\hline
\end{tabular}

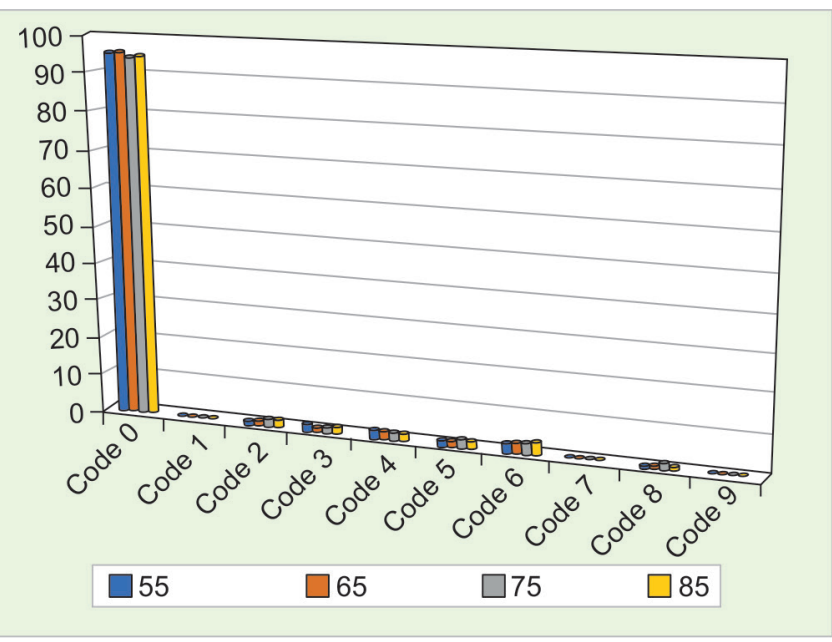

Graph 3: Representation of second deciduous molars caries spectrum as per CAST index

Overall this study depicts the high prevalence of decay and pulpally involved permanent molars, which is recorded by DMFT index would have only been depicted by the ' $\mathrm{D}$ ' component. With the help of CAST index, the extent of dental caries can be assessed accurately. The presentation of results from use of the CAST instrument allowed a more detailed and valid (face and content) reporting of stages of dental caries. ${ }^{15}$ This information can be used by health planners to plan a preventive and treatment program and to increase oral health awareness amongst school going children.

\section{CONCLUSION}

The entire caries spectrum can be visualized by recording the CAST index. CAST index highlights not only on the prevalence of dental caries but also the preventive modalities like fissure sealants, restorations, and consequences of severely affected teeth. The reporting of the caries status according to CAST allows the presentation of a pre-morbidity stage that calls for preventive actions. Due to this, using CAST index as a measurement tool gives an accurate picture of the hidden iceberg of disease (dental caries) prevalent in Indian children which will be useful for oral health planners.

\section{REFERENCES}

1. Selwitz RH, Ismail A, Nigel PH, Pitts B. Dental caries. Lancet. 2007 Jan 6;369 (9555):51-59

2. Moynihan $P$ and Petersen PK. Diet, nutrition and the prevention of dental diseases. Public Health Nutr. 2004 Feb;7(1A):201-26

3. Petersen PE. The World Oral Health Report 2003: continuous improvement of oral health in the 21st century-the approach of the WHO Global Oral Health Programme. Community Dentistry and Oral Epidemiology. 2003 Dec;31:3-24.

4. Downer MC. Do we really need another system for recording caries? Thoughts on ICDAS. Community Dental Health. 2012; 29:258-259. 
5. World Health Organization. Oral health surveys: basic methods. World Health Organization;2013.

6. Banting D, Eggertsson H, Ekstrand KR, Ferreira-Zandoná A, Ismail AI et al. Rationale and evidence for the international caries detection and assessment system (ICDAS II). Ann Arbor. 2005 Sep;1001:109-1078.

7. Monse B, Heinrich-Weltzien R, Benzian H, Holmgren C, van Palenstein Helderman W. PUFA-an index of clinical consequences of untreated dental caries. Community Dentistry and Oral Epidemiology. 2010 Feb;38(1):77-82.

8. Frencken JE, de Amorim RG, Faber J, Leal SC. The Caries Assessment Spectrum and Treatment (CAST) index: rational and development. International Dental Journal.2011 Jun;61(3):117-23.

9. Baginska J, Rodakowska E, Milewski R, Kierklo A. Dental caries in primary and permanent molars in 7-8-year-old schoolchildren evaluated with Caries Assessment Spectrum and Treatment (CAST) index. BMC Oral Health. 2014 Dec; 14 (1):74.

10. Srivastava S, Srii R, Acharya S. An Exploratory Study To Assess Prevalence Of Dental Caries Using An Innovative Index: Caries Assessment Spectrum And Treatment (CAST)
Index In Slum Children, India. International Journal Of Scientific Research. 2017;6(7):208-209.

11. Frencken, J. E., Souza, A. L., Sanden, W. J., Bronkhorst, E. M. \& Leal, S. C. The caries assessment and treatment (CAST) instrument. Community Dentistry and Oral Epidemiology, 2013; 41(1):e71-e77.

12. Malik A, Shauka MS, Qureshi A. Prevalence of Dental Caries Using Novel Caries Assessment Index-CAST. Journal of Dow University of Health Sciences. 2014 Apr 10;8(1).

13. Phansopkar S, Hegde-Shetiya S, Devadiga A, Agrawal D, Mahuli A, Mittal-Mahuli S. Face and content validation of caries assessment spectrum and treatment index among few subject matter experts in India. International Journal of Dental Health Concerns. 2015 Jan;1(1):13-18.

14. De Souza AL, Leal SC, Bronkhorst EM, Frencken JE. Assessing caries status according to the CAST instrument and WHO criterion in epidemiological studies. BMC Oral Health. 2014 Dec;14(1):119.

15. Frencken JE, de Amorim RG, Faber J, Leal SC. The Caries Assessment Spectrum and Treatment (CAST) index: rational and development. International Dental Journal. 2011 Jun; 61(3):117-123. 